\title{
Renal Clearance
}

National Cancer Institute

\section{Source}

National Cancer Institute. Renal Clearance. NCI Thesaurus. Code C75913.

The rate at which a substance is removed from the blood via the kidneys. 